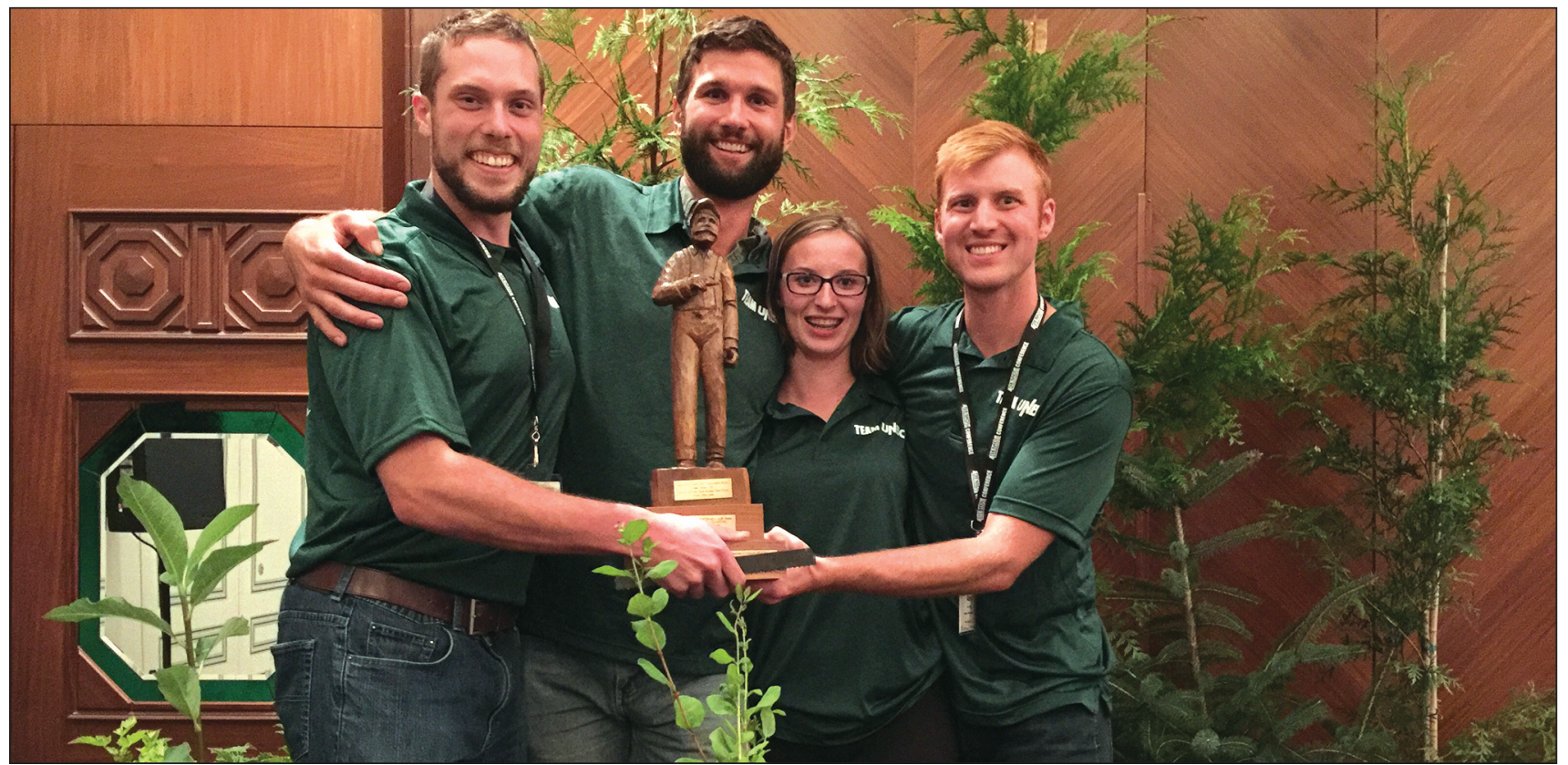

2016 Student Bowl Winners - University of Northern British Columbia + College of New Caledonia. L-R: Eric Matzner (UNBC), Karl Domes (UNBC), Kailin Van Woron (CNC) and Alex Trang (CNC). This special team of university and technical students was put together and coached by Nicolas Dormaar.

\title{
Forest Value Chain Optimization and Sustainability
}

Sophie D'Amours, Mustapha Ouhimmou, Jean-Francois Audy and Yan Feng (eds.). 2017. ISBN 978-1-4987-0486-1. CRC Press, Taylor \& Francis Group, Boca Raton, Florida. 343 pages. US \$129.95 + shipping (hardback). Contact CRC Press at http://www.crcpress.com

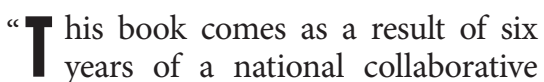
research effort engaged in enhancing knowledge and innovation in the field of value chain optimization in the forest sector. Under the leadership of highprofile Canadian researchers, the guidance of a business-led board of directors, and an incredible team of employees, the Natural Sciences and Engineering Research Council (NSERC) national strategic Value Chain Optimization Network brought together 17 universities, 60 professors and researchers, and more than 55 graduate students, and supported the realization of more than 93 research projects with the support of FPInnovations and more than 74 public and private partners.

This book provides a global perspective on the various issues that the industry has to face as well as to provide some key global strategies that can help coping with those global challenges, such as collaboration, strategic value chain planning, and interdependency analyses. It presents literature reviews, strategic research orientations, assessment of some current key issues, and state-ofthe-art methodologies."

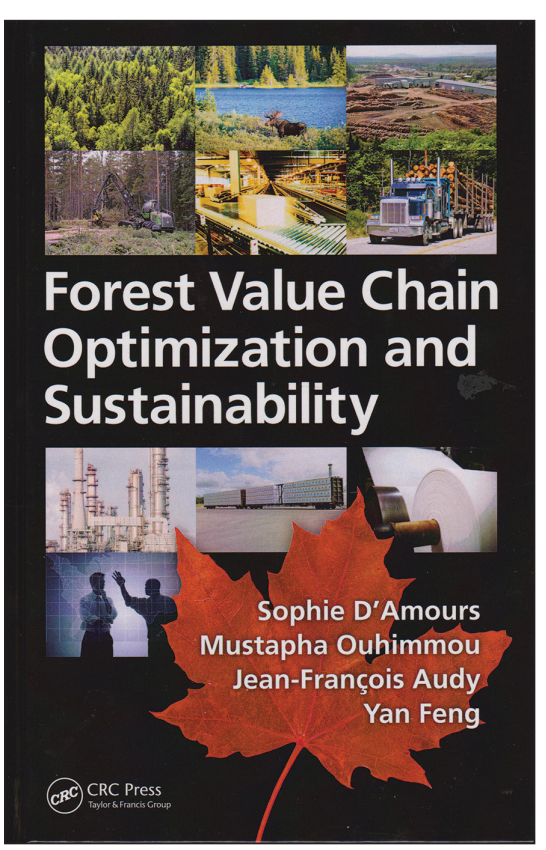

